\title{
Para glória da doença? Leituras do mal de Camões
}

\author{
For the glory of the disease? Readings about \\ Camões' illness
}

\section{LuIS MAFFEl}

Resumo: Prática frequente em literatura portuguesa é o diálogo com Camões. Menos frequente, mas muito produtivo, é transformar Camões em personagem. É Cesário Verde, no seu poema "O sentimento dum ocidental" (1880), quem dialoga com Camões explorando um poderoso topos de entendimento e recriação: a doença, já presente, com diversos sentidos, no poeta do século XVI. A exploração de Camões por esse viés aparece como gesto de encontro e desconstrução do poeta, e será posto em prática por vários autores do século XX em diante, como Jorge de Sena e Armando Silva Carvalho, entre outros.

Palavras-chave: Camões, doença, Cesário Verde, recriação

\begin{abstract}
The dialogue with Camões is frequent practice in Portuguese literature. Less common, but very productive, is to transform Camões in character. Cesário Verde, in his poem "O sentiment dum ocidental" (1880), talk with Camões exploring a powerful topos of understanding and re-creation: the disease, present, with different meanings, in the poet of the sixteenth century. The exploitation of Camões by this mode appears as a gesture of meeting with and deconstruction of the poet, and will be implemented by various authors of the twentieth century onwards, as Jorge de Sena and Armando Silva Carvalho, among others.
\end{abstract}

Keywords: Camões, disease, Cesário Verde, re-creation

* Universidade Federal Fluminense. 
alar de Camões como personagem, em poesia, não é o mesmo que investir numa leitura de algum, alguns, muitos, dos incontáveis diálogos que esse poeta tão moderno ensejou ao longo dos séculos. Dialogar com Camões costuma, em bons casos, fazê-lo aparecer novo e de novo nas obras que o convidam, mas fazer de Camões personagem é um tipo de especulação mais radical. Inventar com Camões é um gesto; inventar outro Camões, outros Camões no plural de um nome já sugestivamente dono de falso e legítimo plural, é diferente, é, em certo sentido, maximizar o gesto e gerar um filho-pai estranho, muitas vezes metafórico, às vezes alegórico, não raro: doente.

Ocorreu-me tão imediatamente isso de filho e pai porque um dos muitos retornados n'As naus de Lobo Antunes é um poeta de nome Luís, que volta a Lisboa arrastando pelas ruas o féretro do pai, não sabendo onde sepultá-lo. Quem o pai da pátria, quem da pátria o filho? Eduardo Lourenço supõe que, se Camões “emprestou forma à existência e ao ser ideal da 'pequena casa lusitana', e assim a subtraiu à informe existência histórica empírica, a ele pertencemos. O que convém é saber como" (LOURENÇO, 1982, p. 164). Como? Invertendo a equação e dando ao poeta o direito de ele também ter um pai, ainda que morto, o que o livra um bocadinho da condenação de ser pai demais, e, por isso, ter até de ser morto para que o filho erija-se em sua subjetividade - nesse caso, dava até para brincar de mais uma, entre tantas, possíveis aproximações do poeta a seu Baco, esta, completamente alheia à sua vontade, pois culpa de uma boa (e culpada? Sobretudo irônica?) recepção: se foi necessário superar Camões, não será ele uma espécie de Baco a ser morto por um ou outro descendente mais perceptivo?

A morte é mote excepcional para se lidar com Camões, vide o féretro loboantunesiano. Centro fogo em poetas, é de um poeta que assombrará depois de morto que sai a voz de "Camões dirige-se aos seus contemporâneos", de Jorge de Sena, poema no qual a imbricação de vozes não rouba do poeta predileto de Sena o papel de personagem-locutor, ou melhor, sujeito ficcionalmente lírico. Quem diz "Podereis roubar-me tudo", para concluir que "será meu,/ tido por meu, contado como meu,/ até mesmo aquele pouco e miserável/ que, só por vós, sem roubo, havereis feito" (SENA, 1984a, p. 162), é a versão seniana de um Camões já cônscio dos vilipêndios que sofrerá após a morte, alguns capazes até de favorecer o poeta em termos de obra e fama. 
Em "Lamento de Luís de Camões na morte de António, seu escravo", de Eugénio de Andrade, sobrevive o poeta pobre a seu fiel companheiro jau de desequilibrada relação, aquele que, segundo relatos biográficos, pedia dinheiro para o retornado não morrer de fome. Vivo, moribundo e diante de um cadáver que não era o de seu pai, o Camões eugeniano diz: "Devias estar aqui rente aos meus lábios/ para dividir contigo esta amargura/ dos meus dias partidos um a um// - eu vi a terra limpa no teu rosto,/ só no teu rosto e nunca em mais nenhum." (ANDRADE, 2000, p. 242) O poema tem apenas uma rima, "um" com "nenhum", rima descendente, pois, apenas numa das estrofes, uma mísera quantidade, ainda que partida, mas, talvez, singular; na estrofe seguinte, nada, nem escravo, nem amigo, nem amante, ninguém.

"O sentimento dum ocidental" é leitura d'Os Lusíadas, publicada, num periódico do Porto, na ocasião do primeiro Dia de Camões, em 1880. No poema, Camões é personagem em vários níveis e vários momentos. Em nível mais imediato, lá está o poeta feito estátua, portanto inócuo, sem voz, mediado, sim, mas pelas famosas "exíguas pimenteiras" que o tornam "monumental" (VERDE, 2010, p. 201) e inacessível aos namorados. Há, contudo, outras presenças camonianas que me assustam mais no poema cesarino, e agora posso entendê-las como adoentadas personificações do poeta que, nelas, está radicalmente longe de seu lugar de gloriosa memória nacional. Uma delas: na sexta estrofe da parte I, "Luta Camões no Sul, salvando um livro a nado!/ Singram soberbas naus que eu não verei jamais!” (VERDE, 2010: 200). Na sétima, a presença massacrante de uma Inglaterra que é poder, metal e vil metal, com seu "couraçado inglês" de onde "vogam os escaleres" e o flamejamento de "louças e talheres" nos "hotéis da moda". Na oitava, como se nada quisessem com isso, "Num trem de praça arengam dois dentistas;/ um trôpego arlequim braceja numas andas;" (VERDE, 2010, p. 200). Outra: o final da penúltima e a inteira última estrofe da parte III, já no começo do fim do longo poema: "Da solidão regouga um cauteleiro rouco;/ Tornam-se mausoléus as armações fulgentes.// 'Dó da miséria!... Compaixão de mim!...'/ E, nas esquinas, calvo, eterno, sem repouso,/ Pede-me sempre esmola um homenzinho idoso,/ Meu velho professor nas aulas de latim!" (VERDE, 2010, p. 203). 
Já comentei, em outro ensaio ${ }^{1}$, esses dois casos. No que toca ao primeiro, o que vai de Camões a um arlequim, com uma poderosa Inglaterra no meio, entendi que o poeta de um passado glorioso fora substituído, num presente opressor, pobre e vazio, por uma espécie de palhaço que só está palhaço porque trabalha. A metáfora da madeira é terrível: "inglês" é o "couraçado" de metal, sendo que a Inglaterra tem a ver com a moda (é magistral o uso do verbo "vogar", que significa, ao mesmo tempo, navegar e estar na moda), enquanto Camões viu naus e o arlequim tem andas, pernas de pau, ambas feitas de madeira, ambas ligadas a um Portugal anacrônico. No segundo caso, sugeri que o deslocamento da "voz enrouquecida" do poeta para um vendedor de loterias, sendo Camões justamente um poeta sem louro n'Os Lusíadas, acusa a permanência da falta de merecimento no poema de Cesário, atentíssimo a questões de pobreza e sociedade em seu tempo. O corolário do lamento é um velho professor poeta, íntimo do idioma amado por Vênus n'Os Lusíadas, pedindo esmola na esquina, indicando o mesmo ensurdecimento sofrido por Camões.

Tudo bem, mas de repente não é só isso, não é bem isso. Falar de Camões como personagem e não apenas interlocutor, sombra, chuva ou trampolim me permite mover a leitura antes feita. Começo pelo segundo caso: se a "voz enrouquecida" do cauteleiro recupera a do Canto $X$, por que não supor que o deslocamento é do próprio Camões para a condição de um trabalhador de fim do século XIX, num capitalismo incipiente mas já injusto, como bem notaram Eça de Queirós e Juliana, em sua pouco pródiga distribuição de cartas? É mais ou menos assim: Camões personagem de Cesário não é o que luta no Sul, pois a lenda é só lenda e o poema é radical, quase torturadamente histórico sem jamais deixar de ser uma homenagem lírica e, logo, elegíaca - à medida que a noite corre e o dia seguinte se aproxima, mais desesperançado e triste vai ficando o tom, e é como se não houvesse nada como um dia seguinte, nenhuma manhã que pudesse ser recebida numa reiteração do lugar-comum da luz. Camões personagem de $\mathrm{Ce}-$ sário é mais de um, o que dá ao poeta o estatuto de maior (diferente não seria mais justo?) que si mesmo, um inevitável Supra-Camões, oriundo da vocação representativa que emana de muitos de seus sentidos. Como já citei, segundo Lourenço, já que Camões "emprestou forma à existência e ao ser ideal da 'pe-

1 Refiro-me a "Cesário e uma cara de seu tempo (que não foi outra)", publicado no número 15 (2009) desta Via Atlântica (p. 131-141). 
quena casa lusitana', e assim a subtraiu à informe existência histórica empírica, a ele pertencemos. O que convém é saber como" a ficção que Camões fez possa se voltar contra ele, quer dizer, encontrá-lo, dando-se (e dando-lhe) o direito de fazê-lo ficção.

Como? Espalhando, dirá Cesário, o poeta em várias personagens que "O sentimento dum ocidental" inventa enquanto as vê nas "nossas ruas" (VERDE, 2010, p. 199), as de Lisboa, o cauteleiro, por exemplo. Antes, Camões não deixa de ser o "trôpego arlequim" que "braceja numas andas", versão oitocentista de um nado que, a todos os títulos, jamais foi nadado pelo poeta, versão citadina de um bufão que saiu dos paços para as ruas. Mas Camões é, acima de tudo, o professor mendicante. As situações são adoentadas, para (terrível) glória da doença: um é rouco, outro, idoso, quase morto mas eterno, sem direito à morte. 0 velho professor é de latim, uma língua que pode funcionar, no nosso caso, ocidentais latinos que somos, como supralíngua, material potencialmente poético, língua de Vênus, da qual o português, segundo a deusa, no primeiro concílio d'Os Lusíadas, é a versão menos corrompida: “ [...] língua, na qual, quando imagina,/ Com pouca corrupção crê que é a Latina" (Os Lusíadas, I, 33, 7-8). Além disso, trata-se de um velho professor, alguém que ensinou ao sujeito lírico algo da ordem da linguagem e da poesia. Camões, é claro, sem qualquer possibilidade de aposentadoria, comendo, não de amigos, como Diogo do Couto viu a personagem biográfica na llha de Moçambique, mas de esmola, como Eugénio de Andrade o formulou e a quem deu voz em "Lamento de Luís de Camões na morte de António, seu escravo". A proposito, a epígrafe do poema de Eugénio é retirada da biografia camoniana escrita por Pero de Mariz: "[...] viveu em tanta pobreza, que se não tivera um jau, chamado António, que da Índia trouxe, que de noite pedia esmola para o ajudar a sustentar, não pudera aturar a vida. Como se viu, tanto que o jau morreu, não durará ele muitos meses" (ANDRADE, 2000, p. 242). Camões é personagem desde sua primeira biografia.

O professor-Camões pede compaixão, n'Os Lusíadas o poeta pediu audição. Compaixão, também? Os leitores, "segundo o amor tiverdes,/ tereis o entendimento de meus versos" (CAMÕES, 2005, p. 117). Compaixão, etimologicamente, indica partilha do pathos, aliança em estado de paixão, logo, de doença. Assim, o professor de língua, da, se pensarmos com Vênus, língua, pede a Cesário semelhante atenção à que Camões pediu, em seu tempo, em/para seu poema despremiado - não é casual a metáfora da esmola, tampouco a expansão da 
personagem também para o vendedor de loterias. Chamando Sophia à roda, é como se o "velho professor" fosse "ao Paço" "pedir que a tença/ Seja paga na data combinada", pois "Este país" o "mata lentamente" em suas esquinas e em seus palácios - "Camões e a tença" é de uma radical aderência ao sofrimento de Camões, ainda que alguns possam ler ali uma excessiva incapacidade reativa em personagem tão potente. Pensando no cauteleiro, é como se o prêmio estivesse na boca de Camões, mas nunca em seu poder, sendo sempre dos outros. 0 Camões de Eugénio, que pede esmola através do jau, e o de Sophia, que pede o que é seu de direito (mas que direito rege a relação entre "Camões e a tença"?), são versões do Camões-professor de latim de Cesário Verde, pedinte, ou seja, socialmente doente, "sem repouso", sem, repito, direito à morte.

Claro que as personagens-Camões n' "O sentimento dum ocidental" não são Camões, ainda que o sejam: estamos entre a ambivalência e a ambiguidade, estamos em deslocamento. A doença é, como bem apontou Susan Sontag, uma condição intermediária, um país que não é a vida, nem a morte, um entrelugar que me arremessa, mais uma vez, ao clímax d'Os Lusíadas, de que não me canso de tratar, justamente por ser o clímax do poema, depois do qual tudo tem de ser lido através da perspectiva do sacrifício. O final do Canto VII, no qual um verso é partido para mudança assustadora de voz e de tom, é justo o momento do começo da morte do cantor.

Um ramo na mão tinha... Mas, ó cego!

$\mathrm{Eu}$, que cometo insano e temerário,

Sem vós, Ninfas do Tejo e do Mondego,

Por caminho tão árduo, longo e vário!

Vosso favor invoco, que navego

Por alto mar, com vento tão contrário,

Que, se não me ajudais, hei grande medo

Que o meu fraco batel se alague cedo.

Olhai que há tanto tempo que, cantando

O vosso Tejo e os vossos Lusitanos,

A fortuna me traz peregrinando,

Novos trabalhos vendo, e novos danos:

Agora o mar, agora exprimentando

Os perigos Mavórcios inumanos, 
Qual Cânace, que à morte se condena,

Nūa mão sempre a espada, e noutra a pena.

(Os Lusíadas, VII, 78-79)

A doença aqui atinge seu paroxismo, pois o poeta revela estar realizando um sacrifício em nome do amor, pois seu caso é qual o de Cânace, que é forçada pelo pai, Éolo, a se matar em virtude de um enlace com o irmão. Enquanto se sacrifica, escreve com a outra mão uma carta de despedida ao amado. O auge da doença enquanto entrelugar, vida na interseção da morte, é haver ainda três cantos do poema a serem cantados por um poeta, além de solitário, abandonado e estrangeiro, morredouro. A imagem que não me deixa é de um sujeito, não mais com a espada na mão, mas tentando evitar que a perda de sangue seja fatal para o cumprimento de seu poema, segurando a ferida com as digitais. É esse o poeta com que se identifica o sujeito lírico de Cesário Verde, aluno de um professor adoentado física e socialmente - não é por isso que Cesário revela ter "luneta de uma lente só", como se recuperasse, não apenas o olho doente camoniano, mas também o são? A luneta acha "sempre assunto a quadros revoltados" (VERDE, 2010, p. 202), pois há um olho perdido, fechado, que sobrecarrega o que está sobrevivido e torna-o, talvez, ainda mais capaz de ver.

Antes da aparição do cauteleiro, perto do fim da parte III do poema, outra identificação de Cesário com um Camões distante de qualquer esplendor físico: "Mas tudo cansa" (VERDE, 2010, p. 203), expressão que ecoa o célebre "No mais, Musa, no mais" (Os Lusíadas, X, 145, 1) do começo do fim d'Os Lusíadas, quando o Canto $X$ deflagra um poeta que está morrendo, mas não morreu e pode escolher mais vida em nome da velha causa (se "o vosso peito", Rei, "Dina empresa tomar de ser cantada" [Os Lusíadas, X, 155, 5-6]) - e Cesário, mesmo cansado, anda e anda até chegar ao fim de seu discurso, de seu texto. Perceber um Camões doente $\mathrm{n}^{\prime}$ "O sentimento dum ocidental" permite-me entender meIhor a doença do próprio viandante, dita nos versos de abertura da segunda quadra da parte II: "E eu desconfio, até, de um aneurisma/ Tão mórbido me sinto, ao acender das luzes;" (VERDE, 2010, p. 201) ainda que não exista exatamente uma morbidez camoniana, a doença da personagem-Camões não deixa de recuperar a doença formulada pelo próprio Camões. Marcia Arruda Franco investigou as 
"Drogas afrodisíacas e psicoativas em Camões" em texto que tem como um de seus fitos principais, a partir da leitura que o poeta faz de Garcia da Orta, para cujos Colóquios dos simples e drogas e cousas medicinais da Índia escreveu a ode "Aquele único exemplar", o "saber científico" de que os versos lançam mão para "construir a sua imagem dos efeitos de Amor sobre o sujeito enamorado" (FRANCO, 2012, p. 87).

Como motivo para as ervas, a doença. Marcia se refere à Canção $X$, que apresenta um veneno amoroso inoculado no sujeito desde o berço. A ensaísta diz algo bastante importante sobre a doença em Camões: "A metáfora da doença amorosa assume vários níveis de gravidade na obra de Camões. Ela é bem menos séria nos dois primeiros textos da série de 3 de redondilhas publicadas em 1595, feitas a damas doentes" (FRANCO, 2012, p. 88). Um dia, pretendo merguIhar na maior gravidade referida por Marcia, a fim de meditar sobre um Camões entre o mal e a busca pela cura, ou pelo antídoto, enquanto se intensifica sua melancolia, tão bem estudada por um Vítor Aguiar e Silva que afirmou a "melancolia" exprimir-se "em Camões como a consciência e o sentimento angustioso da dispersão da vida no espaço" (SILVA, 1994, p. 220), como o índice mais concreto de que o homem que, "ante o abandono ou a indiferença do seu Criador", segundo o insigne camoniano, (SILVA, 1994, p. 223), se converteu no "bicho da terra vil e tão pequeno" (CAMÕES, 2005, p. 222) da Canção IX.

Aqui, contudo, não penetro ainda nessa zona da doença em e para Camões, mesmo que todas, as, por assim dizer, sérias e menos sérias, se encontrem na esquina fundamental da paixão, ou das paixões. Meu escopo é o Camões doente que se oferece, simpático, à compaixão de alguns de seus melhores leitores, de seus melhores colegas, Cesário Verde sobre todos. A segunda das três redondilhas referidas por Marcia é cheia de um erotismo bem-humorado. Destaco a primeira oitava, a fim de pensar melhor no que seja "diferença" nesse universo em que a moléstia é um estado de alta excepcionalidade:

Não sabendo Amor curar,

foi a doença fazer

fermosa para se ver,

doce para se passar.

Então, vendo a diferença

que há de vós a toda a gente, 
mandou que fôsseis doente

para glória da doença.

(CAMÕES, 2005, p. 49)

Não sei se vem ao caso pensar na "configuração romântica da singularidade", dentro da qual, por exemplo, a tuberculose "era considerada uma forma de promoção da pessoa, uma forma de individualizá-la entre tantas outras, de torná-la mais inteligente, mais sedutora" (DASSIE, 2011, p. 19), segundo Franklin Alves Dassie, numa tese de doutoramento sobre doença em (alguma) literatura. Talvez venha, posto que a singularidade é um problema para Camões, ainda que o interesse do poeta seja pela possibilidade de o corpo doente ser encenado dentro do texto (o que permitiu a Cesário e outros adoecerem o vate e a relação com ele), não em qualquer biografia que o texto procurasse recuperar - não tem relevância alguma, para a leitura que fizermos do texto, sabermos se a Dama doente da cantiga citada realmente existiu, e se era ou não doente de fato.

A redondilha que escolhi citar, escolhi-a porque nela está em jogo, mais que a possibilidade de contágio, o desejo pelo contágio, e o desejo, como sabemos, é o que faz o amor em Camões se mover. Amor por vezes não sabe curar, pelo contrário, só sabe adoecer, o que ecoa, como Marcia Arruda Franco investiga em seu texto, a biografia do poeta, muitas vezes doente de doenças passadas por amores - é com um Camões sobrevivente de doenças de quem amou muito e muitas, aliás, que Sena se solidariza no "Super flumina Babylonis". Não obstante, a biografia que se vê num texto é a que o texto encena, enceta, e se eu citei o Pedro de Mariz recolhido por Eugénio para concluir que Camões é personagem desde sua primeira biografia, a epígrafe do conto de Sena, vinda de Latino CoeIho (Luís de Camões, Lisboa, 1580) exige-se citar: "É que os génios não têm, não precisam de ter biografia" (SENA, 1984b, p. 155). Faz todo o sentido recuperar a abertura do magnífico texto, cujo encerramento não é uma cena de doença, é, apesar da doença, uma cena de escrita:

A ascensão da estreita escada escura, e tão a pino, com os degraus muito altos e cambaios, era, sempre que voltava a casa, uma tortura. À força de equilíbrios, meio encostado à parede, cuja cal já se esvaíra havia muito e até nas suas costas, e apoiando-se em viés uma das muletas no extremo oposto do degrau de cima, ia subindo cuidadosamente, num resfolegar de raiva pela lentidão. Toda a 
unção adquirida na conversa com os frades de S. Domingos, a cujas prelecções regularmente assistia, ficando depois a discretear com eles, se perdia naquele regresso a casa, ao fim da tarde, e mal se recompunha no repouso à janela, sentado no banquinho baixo, comido o caldo, e ruminando memórias e tristezas [...]. (SENA, 1984b, p. 155)

Um poeta doente ainda, como dirá a parte final do conto, escreve, ou seja, assume seu compromisso com aquilo que só ele pode fazer, ou melhor, com aquilo que ele só pode fazer, ao contrário da personagem andreseniana, cuja reação é pouca além de morrer lentamente:

Tudo falhara, tudo, e a própria poesia o abandonara, receosa dos seus olhos de alma penetrantes que viam o fundo das coisas. $\mathrm{O}$ poço com as formas flutuando. Mas era um grande poeta, transformava em poesia tudo o que tocava, mesmo a miséria, mesmo a amargura, mesmo o abandono da poesia. (SENA, 1984b: 166)

Mesmo a doença, alguém poderá dizer. O poeta de Sena é uma espécie de trágico alquimista, produzindo um ouro que jamais se tornará fonte de lucro ou riqueza para aquele que o produziu. A poesia, aí, é uma prática amorosa, e Amor, de fato, por vezes não saber curar. Para glória amorosa da doença, ainda bem, pois há de haver contágio, nem que a consequência seja um sacrifício como o do final do Canto VII ou a encenação da escrita de "Sôbolos rios" no fim do conto seniano. Na primeira oitava da redondilha citada, além da glória, aparece um vocábulo que me sabe extremamente significativo: diferença: "Então, vendo a diferença/ que há de vós a toda a gente,/ mandou que fôsseis doente/ para glória da doença". O sujeito lírico, vendo a amada na cama, antes de querer cair no leito com ela, entende que, se ela é doente, a doença só pode ser um índice de diferença, e a rima entre os dois vocábulos só incrementa a semelhança - Camões, como os românticos entenderam bem, gostava imensamente da singularidade. Portanto, se amor é doença, amor é também diferença, distinção, galardão que representa, a um só tempo, a glória da especialidade, do amor e do cruzamento entre vida e morte. Não percamos de vista a necessária distinção que há de existir para que se tenha direito ao sacrifício, que, revertido, se tornará fresta para a superação do tempo de apenas uma vida. 
A relação entre doença, diferença e amor, formulada apaixonadamente n'Os Lusíadas e na lírica camoniana, não deixa de reaparecer em muitas das figurações de Camões como personagem de outros autores. A paixão, a compaixão que Cesário e camaradas nutrem pelo e com o enfermo mais glorioso entre os derrotados, ou mais derrocado entre os gloriosos, é sintoma de amor, sentimento de ocidentais que movimenta e mobiliza o poeta, nem que, para isso, seja preciso, e bem-vindo, não o salvar de coisa alguma. Por exemplo, não o salvar de sua "luneta de uma lente só", ou de sua zarolhice, como faz Armando Silva Carvalho num de seus livros mais contundentes, Armas brancas, escrito em 1975 e publicado em 1977. Em 43 poemas que possuem frenesi nominalista e interlocutivo, diversos nomes são citados, de Jorge de Sena a Pessoa, de Bach a Pasolini, de Rilke a Sollers, e os intertextos são muitíssimos. Camões aparece, como em outros casos, em deslocamento, sendo e não sendo ele, feito, não intertexto apenas, mas personagem mediado por outros poetas, Álvaro de Campos, por exemplo: "Mas não queiras chorar aqui sobre o cais clássico/ porque cairás na estilística de fundo/ apavorado e com o braço de fora/ como o grande Zarolho" (CARVALHO, 2006, p. 200). Em nota de fim, escolha irônica e ironicamente posta num livro de poesia, lê-se: "O grande Zarolho é uma forma terna de evocar Camões" (CARVALHO, 2006, p. 204). A palavra, que já aparece no "Camões na Ilha de Moçambique" de Sena, ganha "z" maiúsculo em Armando, tornando-se própria.

Claro que a "forma terna" é um bocado irônica, mas não será terna mesmo? A questão é, outra vez, de entrelugar: Camões é zarolho porque tem um olho só, posto que perdeu o outro sabe-se lá quando e como, mas não o será também porque viu, de seu ponto de vista, como um danado? A ternura é também um pouco cômica, pois zarolho é substantivo irreverente, feito, agora, substantivo próprio, personagem, pois. E o grande Zarolho, com " $z$ " maiúsculo, está "apavorado", ainda vesgo, e, depois, estará por perto das Tágides, "as robustas musas do enorme Zarolho" (CARVALHO, 2006, p. 201). Mais ironia: a personagem é "grande", em seguida "enorme", sempre posta, todavia, em sua condição vesga, vedora mas parcialmente cega, e, porque parcialmente cega, ainda mais vedora. Para glória da doença, da zarolhice, as "robustas musas do enorme Zarolho" são companhias fecundas para um amante doente, ainda trêfego e dado à reinvenção pela língua que ajudou a inventar e pelos poetas que se dão a reinventá-lo, reinventá-la. 
Nesse sentido, condenado a uma vida criativa e metamórfica ao longo de muitos séculos, Camões feito personagem, afinal, ganha, especialmente de Cesário Verde em diante, o belíssimo direito de morrer. É como se todos os poetas citados, e tantos outros, resolvessem adoecer o poeta a fim de lhe dar o direito de sucumbir a partir do sacrifício do final do Canto VII, tirando-lhe a mão da ferida fatal e pondo-a em outros lugares de interesse. $\mathrm{O}$ amigo de seu escravo jau, o professor de latim, o transformador de miséria em poesia, o pedinte no Paço, o Zarolho etc., todos doentes, são já possibilidades abertas por uma grande coragem desses poetas, coragem de dupla face: por um lado, ler Camões dentro da poesia portuguesa, permitindo que contágio perigosíssimo não deixe de ter lugar numa espécie de desconcertado presente contínuo. Por outro, matar Camões, fazendo surgir dali o que Maria Gabriela Llansol entendeu como ninguém e traduziu num nome próprio que pluraliza o fingido plural do nome Camões: Comuns.

O substantivo próprio, não comum mas Comuns, de Da sebe ao ser é um gesto extremo de compaixão e abertura, indício de que a contaminação que levou Camões à morte é o que leva suas versões, sua leitura, a uma vida de muita ficção, fricção e superação do destino. Pergunto mais uma vez: quem é o pai da pátria, quem o filho? A lição realmente já está em Cesário, e depois nos colegas: multiplicando o poeta, superando-o, não fica indiciada que já está potencialmente em Camões, para contentamento descontente de um Pessoa que inventou o camoniano Álvaro de Campos, um supra-Camões? Comuns, plurais, as personagens-Camões não indicam uma surpreendente capacidade heteronímica no poeta que tanto se permite (re)inventar?

\section{Referências}

AGUIAR E SILVA, Vítor. As canções da melancolia. In. Camões: labirintos e fascínios. Lisboa: Cotovia, 1994. pp. 209-228.

ANDRADE, Eugénio de. Poesia. Porto: Fundação Eugénio de Andrade, 2000.

ANDRESEN, Sophia de Mello Breyner. Dual. Edição definitiva. Lisboa: Caminho, 2004.

ARRUDA FRANCO, Marcia. Botânica, amor e poesia: psicoativos, afrodisíacos e a mulher.

In. Camões e Garcia da Orta em Goa e em Portugal (séculos XVI e XIX). Coimbra: Centro Interuniversitário de Estudos Camonianos da Universidade de Coimbra, 2012. pp. 87-109. 
CAMÕES, Luís de. Os Lusíadas. Org. Emanuel Paulo Ramos. Porto: Porto editora, 1978. . Rimas. Edição de Álvaro J. da Costa Pimpão. Coimbra: Almedina, 2005.

DASSIE, Franklin Alves. Cenas e cenários da doença na literatura. 142 p. Tese (Doutorado em Literatura Comparada) Universidade Federal Fluminense, 2011. LLANSOL, Maria Gabriela. Da sebe ao ser. Lisboa: Rolim, 1988.

LOBO ANTUNES, António. As naus. Lisboa: Dom Quixote, 1988.

LOURENÇO, Eduardo. Tempo português. In: A nau de Ícaro seguido de Imagem e miragem da lusofonia. Lisboa: Gradiva, 1999, p. 105-110.

QUEIRÓS, Eça de. O primo Basílio. Rio de Janeiro: Rio Gráfica, 1987.

SENA, Jorge de. Trinta anos de poesia. 2. ed. Lisboa: Edições 70, 1984a. . Antigas e novas andanças do demónio. 4. ed. Lisboa: Edições70, 1984b.

VERDE, Cesário. Poemas reunidos. Introdução e notas Mario Higa. São Paulo: Ateliê, 2010.

Submetido em: 28-12-2015

Aprovado para publicação: 24-06-2016 